\title{
A Typology of Revenue Models for Community Health Worker Programs
}

\author{
Richard Zang \\ The Pennsylvania State University \\ University Park, PA 16802 \\ rfz5006@psu.edu
}

Stephanie Jeong

The Pennsylvania State University

University Park, PA 16802

sdj5092@psu.edu

\author{
Meryn Robinson \\ The Pennsylvania State University \\ University Park, PA 16802 \\ meryn.robinson@gmail.com \\ Stephen Suffian \\ The Pennsylvania State University \\ University Park, PA 16802 \\ stephen.suffian@gmail.com
}

\author{
Khanjan Mehta \\ The Pennsylvania State University \\ University Park, PA 16802 \\ khanjan@engr.psu.edu
}

\begin{abstract}
Community Health Workers (CHWs), a presence in almost every developing country, have proven instrumental in improving their communities' health. CHWs in most countries are volunteers relying on programs with marginal government support and irregular external funding. A lack of incentives is a fundamental challenge to realizing the full potential of $\mathrm{CHW}$ programs. CHW programs often suffer from high attrition rates, poor efficiency and lack of coordination and accountability. This article argues that there is a dynamic interdependence between CHW programs and entrepreneurial mobile health (mHealth) systems trying to become economically self-sustaining. This interdependence can be leveraged to design effective, efficient and sustainable mHealth ventures that enable, complement and augment CHW programs with the shared objective of improving the healthcare system in developing countries. This article presents a typology of eight business models where CHWs function as the channels and champions for mHealth ventures. The target audiences of this article are innovators and entrepreneurs seeking to launch sustainable mHealth ventures by leveraging the civic infrastructure of community health workers in developing countries.
\end{abstract}

Index Terms - business models, community health workers, entrepreneurship, preventive care

\section{INTRODUCTION}

The nature of disease is changing around the world with non-communicable diseases (NCDs) gradually surpassing infectious diseases as the leading cause of mortality. ${ }^{1}$ This double burden of acute and chronic disease poses an enormous challenge for developing countries with fledgling healthcare systems. Community Health Worker ( $\mathrm{CHW}$ ) programs have emerged as one of the most effective ways to provide primary health care at the community level in developing countries around the world - from Brazil to Ethiopia, Pakistan, and Vietnam. ${ }^{2,3}$ CHWs connect 
communities to the health care system by providing services such as illness prevention, basic treatment, hygiene and sanitation, data collection, and health education. CHW programs around the world are proven to have a positive impact on their communities, even while working with limited resources. ${ }^{4}$ Consequently, a wide range of $\mathrm{CHW}$-centric electronic health (eHealth) systems that leverage the ubiquity of cellphones and the internet are being developed and fieldtested. These mobile health (mHealth) systems can enhance the efficiency and efficacy of CHWs while giving such projects their much-needed champions and channels to communities. mHealth has been used to implement programs such as telemedicine systems, awareness campaigns, and data collections. The symbiosis of CHWs and mHealth systems can be a game-changer for global health. ${ }^{5,6}$

CHW programs and mHealth systems have one common challenge - a dearth of sustainable business models. Major challenges to $\mathrm{CHW}$ programs include inconsistent training, lack of equipment and supplies, absence of organizational structures that ensure standardization and quality assurance, and - most importantly - lack of incentives. The vast majority of CHWs are volunteers driven by passion for community health and pride in their work. The current system suffers from high CHW turnover with frustrated or strained volunteers who feel underappreciated. While compensation from the government is an often-cited proposed solution, it is not feasible in many situations. There is growing interest amongst CHWs to derive at least a part of their income from their community health activities. Accordingly, some countries like Bangladesh and Pakistan encourage their CHWs to sell health commodities like medicines, contraceptives, and feminine hygiene products to earn a small income. These income generation activities do not replace their primary voluntary duties but do build upon the trust and social capital that the CHWs have in their communities. In essence, the sustainability of $\mathrm{CHW}$ programs is a central issue in most countries due to inconsistent funding from the government and/or large non-profits. ${ }^{7,8}$ There is a need to develop practical, innovative and sustainable models where CHWs can derive supplemental income without compromising their core duties or allegiance to their communities.

On parallel lines, a major challenge facing mHealth programs in particular, or eHealth programs in general, is "pilotitis", either a lack of intent or inability to scale up beyond the pilot phase. ${ }^{9}$ For example, in Uganda, 23 mHealth programs did not advance past the pilot phase between 2008 and 2009. In India, there were more than 30 similar projects that did not advance past the pilot stage in $2009 .{ }^{10}$ The proliferation of pilot projects was so extreme that the Ugandan government declared a moratorium on mHealth pilots, representing a key stakeholder calling for sustainability. ${ }^{11}$ The problem, as summarized by Dr. Esther Ogara, the head of eHealth for the Ministry of Health in Kenya, is that "many projects...begin without an idea of who will fund them in the long run." ${ }^{\prime 2}$ Donors are the largest source of funding for many of these programs, with the government and out-of-pocket payments as the next largest contributors ${ }^{13}$. Donors are often reluctant to assume financial responsibility for on-going projects, and cash-strapped governments cannot be the catch-all funding mechanism to fall back on for these mHealth projects. ${ }^{12}$ And so, once the initial funding is exhausted, mHealth programs often wind down to become another successful experiment but failed long-term venture.

What are the pathways to transform CHWs from volunteers to entrepreneurs? How can CHWs leverage mHealth programs to supplement their incomes while enhancing the reliability, accessibility and accountability of the entire system? This article presents a typology of business models for $\mathrm{CHW}$ programs to advance towards self-reliance by providing opportunities for income generation alongside routine visits and other responsibilities. The success and 
sustainability of several mHealth solutions in developing countries relies on their successful adoption by CHWs and other stakeholders. We posit that the economic success of mHealth ventures, CHWs, and the communities they serve are interdependent. The purpose of this business model typology is to inform and inspire innovators and entrepreneurs in their quest for win-win solutions for global health projects that leverage mHealth systems, public health programs, and the lean civic infrastructure of Community Health Workers.

\section{Typology Of Revenue Models For CHW Programs}

The business models presented in this article were identified, refined and articulated over a fiveyear period. The genesis of this article can be traced to a study of the failure modes of 35 entrepreneurial telemedicine and mHealth ventures. ${ }^{14}$ These failure modes were juxtaposed with our experiences developing and implementing telemedicine and primary health technologies in East Africa. The business models were categorized based on the relationship of varying stakeholders and the nature of the transactions between them.

The business models presented in this article are classified into eight categories: Additional Services, Products, Education, Advertisement, Data Collection, Referrals, Home Care, and Regulatory. When referenced, "routine services" refers to the services and responsibilities that the CHWs conduct on a regular basis. Routine services include visiting homes to provide treatment of simple and common illnesses, keeping records, collecting data, providing health education regarding nutrition and surveillance, sanitation precautions, and infectious disease management. CHWs also educate communities about malaria prevention, kitchen gardens, acute respiratory diseases as well as family planning, birthing care, HIV/AIDS and STIs. As shown in Table 1, the business models described in this paper implicate a wide swath of stakeholders. The value propositions for each of the stakeholders, as well as potential revenue streams, are explained with the help of real-world examples. Some examples are taken from actual businesses while others are illustrative of an appropriate use case. Revenue streams in the model diagrams are shown as dotted if they are conditional on the implementation method of the business model and solid if they are required for the model under any implementation. These business models are based on market-pull rather than technology-push. The primary question is not "How can we leverage CHWs to develop sustainable mHealth systems?" but rather "How can we leverage mHealth systems and other new technologies as tools to enable, empower, and augment CHWs as they fulfill their value propositions?" 


\section{TABLE I}

CHW-MHEALTH BUSINESS MODEL STAKEHOLDERS

\begin{tabular}{|c|c|c|}
\hline Stakeholder & Symbol & Explanation \\
\hline Community Health Worker (CHW) & & $\begin{array}{l}\text { Members elected to improve } \\
\text { community health } \\
\text { Interested in augmenting their } \\
\text { livelihoods through health services }\end{array}$ \\
\hline Communities & & $\begin{array}{l}\text { Communities served by } \mathrm{CHWs} \\
\text { Livelihoods are correlated to health; } \\
\text { community members are increasingly } \\
\text { willing to pay small amounts for } \\
\text { health needs }\end{array}$ \\
\hline Organization/Government & & $\begin{array}{l}\text { Non-profit, business, or government } \\
\text { entity focused on supporting CHWs } \\
\text { Non-profit: interested in lean } \\
\text { approaches to reach more } \\
\text { communities and increase their impact } \\
\text { Business: interested in exploring base- } \\
\text { of-pyramid markets to increase their } \\
\text { profits } \\
\text { Government: typically cash-strapped } \\
\text { and reliant on external donors; } \\
\text { Seeking lean approaches to fight the } \\
\text { double burden of disease }\end{array}$ \\
\hline
\end{tabular}

\section{Additional Services Business Model}

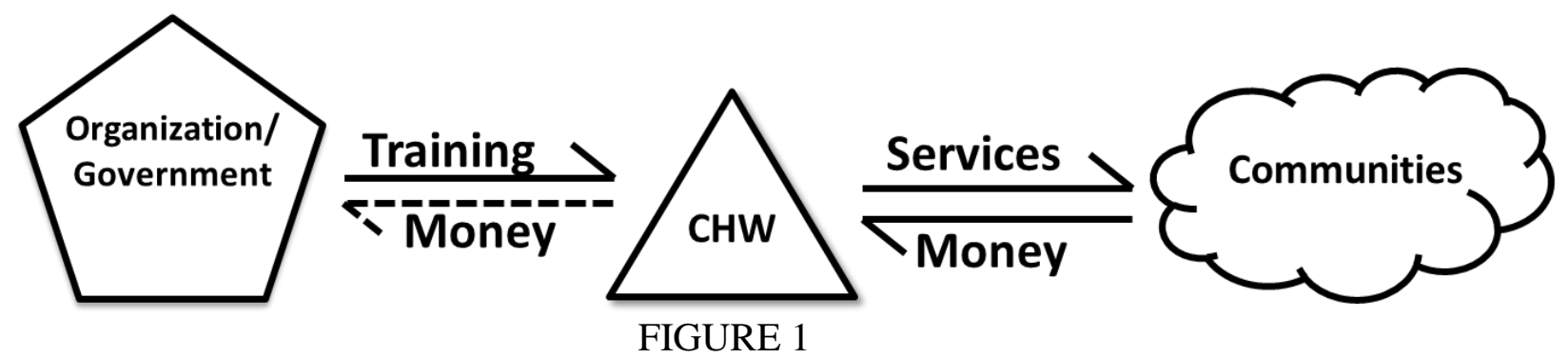

ADDITIONAL SERVICES BUSINESS MODEL

- The CHW is trained by the CHW program and provided necessary equipment and supplies

- The CHW conducts routine services in the community

- The CHW offers additional services during the routine visits

- Community members pay for additional service(s) that the CHW offers

In this model, the $\mathrm{CHW}$ is trained by an external entity to use specific equipment to provide additional services in the community. Depending on how the incentives are structured, the $\mathrm{CHW}$ could directly pocket the additional payments or return them to the venture and receive a salary and/or commissions. The salaried case would be more appropriate if the services may take some time to generate demand and CHWs are unwilling to take the full risk of purchasing equipment 
early on. As demand rises, the direct payment case would lead to better incentives for CHWs to offer the additional service to as many people as possible.

For example, in Nyeri, Kenya two CHWs walk around busy marketplaces as well as rural areas offering weight, temperature, blood pressure, and height measurements. They receive a portion of the money gained from the services they offer, and the rest goes to their employer, who hires the CHWs, trains them to use the necessary equipment, and then provides the equipment the CHWs carry with them to take the measurements. ${ }^{15}$ These CHWs are also trained to utilize a mobile website to offer secure health profiles, where community members can track their health over time. This additional service provides people with the opportunity to monitor their health without having to travel to a hospital, while allowing CHWs to more effectively manage community well-being.

\section{Additional Products Business Model}

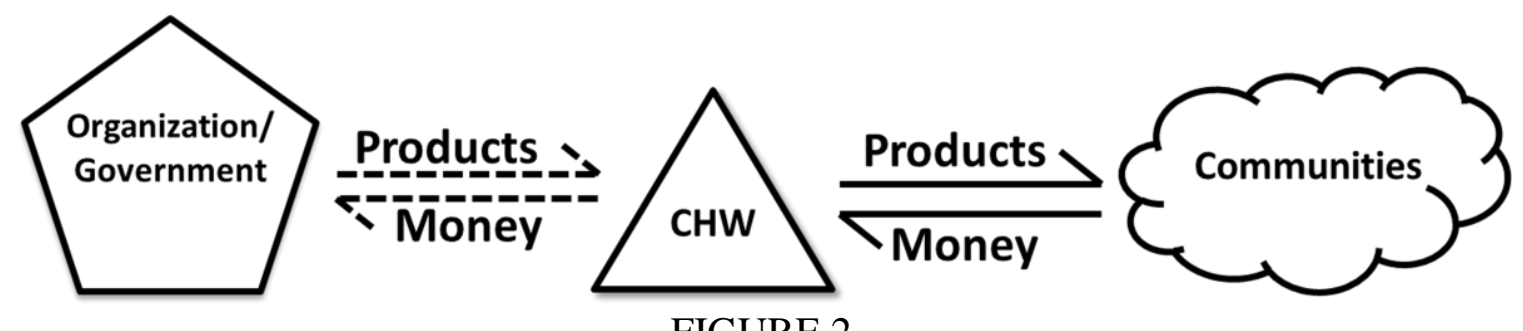

FIGURE 2

ADDITIONAL PRODUCTS BUSINESS MODEL

- The CHW conducts routine services within the community

- The CHW sells additional products to community members for a small profit

In addition to offering new services during house visits, CHWs could also generate income by offering healthcare products to community members. These products could be personally acquired or supplied by an external entity. $\mathrm{CHWs}$ would validate that a new product may be useful to certain community members and then sell it during house visits for a small profit. Some products may be acquired by the CHWs themselves while others, especially those with supply chain difficulties, might be supplied by external organizations. The appropriate price points could be initially suggested by the organization, but CHWs should be the ultimate arbiters of price as they have the best knowledge of what their communities can (or are willing to) pay and what profit margins are appropriate.

LivingGoods $^{16}$ is an organization that equips health promoters to become microentrepreneurs in addition to their traditional communal duties. They offer both an mHealth information texting component and a supply chain component for low-cost, health-conscious products. A CHW is trained to become a micro-entrepreneur by local LivingGoods representatives. The $\mathrm{CHW}$ signs up community members for relevant LivingGoods programs, such as SMS treatment reminders and automated stage-appropriate pregnancy care texts. The CHW sells a vast array of products such as solar panels, clean-burning stoves, sanitary pads, and fortified porridge. Community members who are signed up for the SMS-based messaging also receive periodic promotions and related health benefits regarding LivingGoods products. The $\mathrm{CHW}$ generates income through the sale of these products while acting as the last-mile of the 
supply chain for LivingGoods. This benefits both the LivingGoods brand and community members previously unable to access these healthy living products.

\section{EDUCATION BUSINESS MODEL}

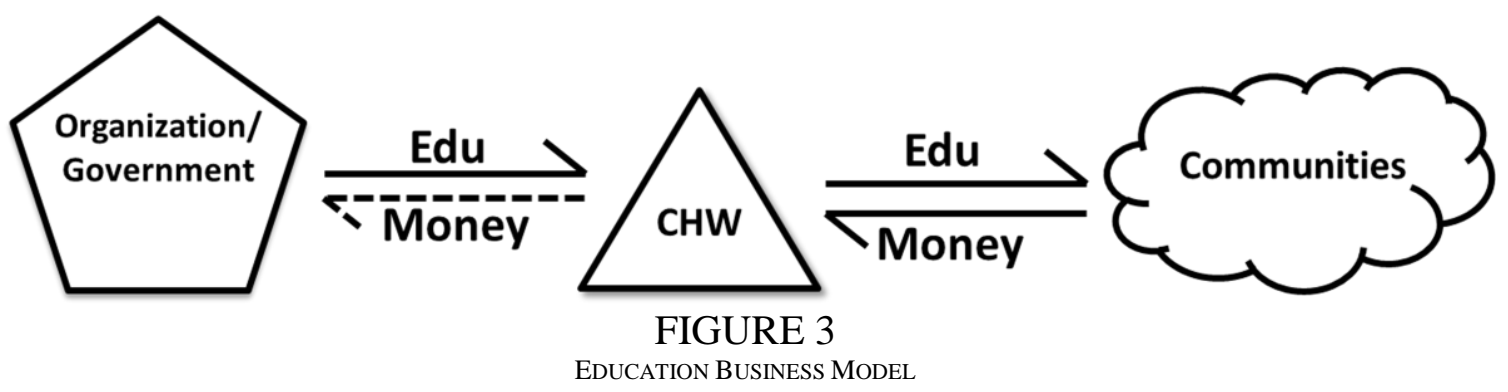

- The CHW is educated about relevant health issues and how to conduct community education seminars

- The CHW conducts educational seminars and workshops for the community

- Community members or external organizations pay CHWs

One of the goals of a CHW program is to educate the community on relevant primary health topics including basic hygiene, proper nutrition, and maternal health. However, it is possible for $\mathrm{CHWs}$ to partner with external organizations to provide broader educational opportunities for interested community members at a cost. In one approach, after providing traditional services and information, $\mathrm{CHWs}$ could offer additional written or electronic material for a small fee. This would have the greatest chance of success when the material is significant and leads to obvious positive outcomes. For example, in an area with a largely agrarian culture, lower back and neck problems may be prevalent. ${ }^{17}$ A highly-visual book on exercises that mitigate this pain would prove valuable for people whose life requires daily manual labor. The CHW would also sign up members to any available mHealth programs such as text-based awareness campaigns. For members who seek more information, the $\mathrm{CHW}$ could partner with local cyber cafés for members to be led through relevant health websites while developing their computer skills for an additional fee.

A telecommunications company partners with a non-profit to train $\mathrm{CHWs}$ on internet literacy, basic computer skills, and methods for teaching these skills to others. The non-profit provides CHWs with text-based services in their area that provide basic health information at no cost. Several organizations already conduct such activities in different world regions. In India, CycleTel $^{18}$ provides family planning advice over SMS for free. In South Africa, txtAlert ${ }^{19}$ provides free timely reminders for tuberculosis and antiretroviral medicines. In Kenya, the Diabetes Management Information Centre provides text-based information for those afflicted with diabetes. During house visits, CHWs sign community members up for the relevant textbased services. For an additional fee, CHWs invite members to an internet literacy course hosted at the local cyber café. Access to the internet provides community members the ability to further learn about specific diseases, nutritional information, and other applicable health topics. A small portion of this course fee goes to the non-profit, with the majority going to the $\mathrm{CHW}$. The telecommunications company subsidizes data usage during these sessions and negotiates with the cyber café owner for usage of the space; both parties are willing to donate in return for the development of new customers. 


\section{AdVERTISING Business MODEL}

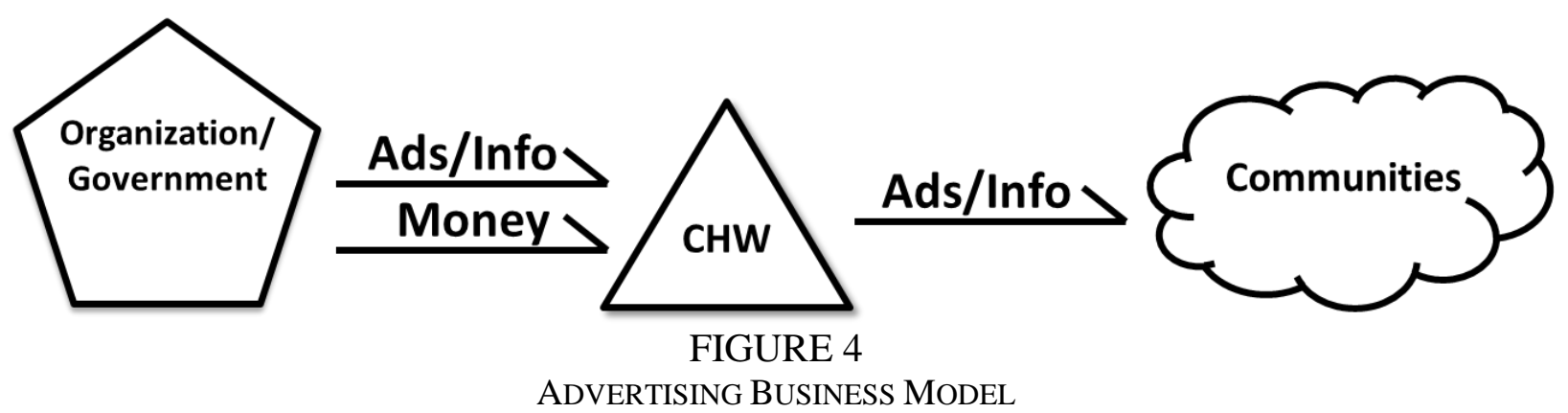

- An external entity trains CHWs and provides necessary advertising supplies

- The CHW conducts routine services in the community

- The CHW educates and advertises products to community members

- The external entity pays CHWs a stipend

In rural communities without easily accessible medical facilities, CHWs assume the role of connecting community members to healthcare facilities. As part of this role, they are trusted to distribute updated medical information such as new health initiatives by the government, services provided by non-profits in a nearby town, temporary medical camps, or products that help with illnesses. The organizations providing these products and services can access these communities more effectively by compensating the CHWs to endorse and market their products or services. These organizations would train the CHWs and provide educational materials to subsequently share during routine home visits. The CHWs are compensated for simply providing this material or may be given a commission on eventual purchases.

Paid advertising must be carefully conducted to avoid conflicts of interest between the $\mathrm{CHWs}$ role as a health provider and their desire to generate income. While a commission might lead to greater sales, it can also incentivize false health advice. A salaried payment or payment per marketed household may be a more ethical route. In these cases, accountability measures must be introduced to ensure that CHWs are truly following the instructions of the organization. For example, CHWs could collect phone numbers from their households. The organization could then make randomized follow-up surveys to ensure that those households received the proper marketing materials.

CHWs partner with a new local company that produces sugar substitutes. The company hires a non-profit to train the CHWs in measuring blood sugar and handling the glucometers. The company than provides the glucometers to the CHWs. During house visits, the CHWs offer blood sugar tests to community members. If they find people who are at risk for diabetes, they offer them free text messaging-based services, such as SMS Diabetes ${ }^{20}$, which send periodic messages regarding proper diabetes management. $\mathrm{CHWs}$ then explain how using a sugar substitute could improve their ability to manage the disease. The community members receive a free sample to ensure that the substitute tastes similar. They are then referred to the nearest store that carries the product. The CHW enters the location of the user on a mobile application, so that the sugar substitute company can monitor the effectiveness of this advertising campaign. 


\section{Data Collection Business Model}

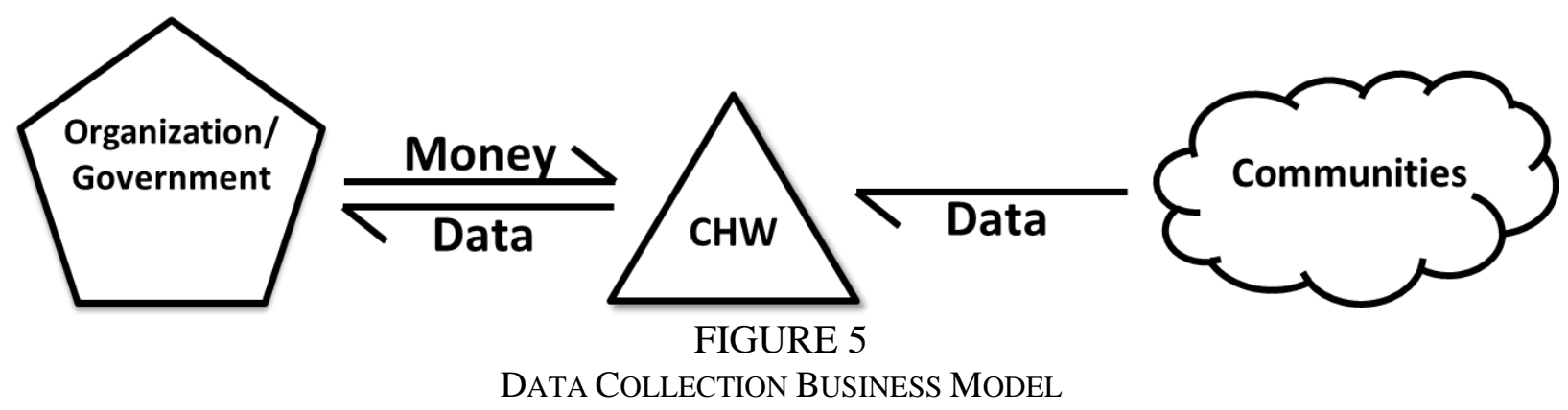

- The CHW conducts routine services in the community

- The CHW collects pertinent information requested by the government, a for-profit or a non-profit entity

- $\quad$ The $\mathrm{CHW}$ is paid a stipend for his/her efforts

CHWs are frequently employed to collect clinical information from their communities on behalf of health organizations or government entities due to their role as trusted community members. They could conduct additional surveys during house visits offering organizations unique access to data ranging from the spread of diseases, to the prevalence of malnutrition, to maternal health indicators. Monetizing this process incentivizes CHWs to devote more time and effort to proper data collection. A major caveat of this model is quality control. Similar to the services model, CHWs could be paid a fixed salary or paid per data item. Similar to previous models, caution should be taken when paying CHWs per entry as this may incentivize false or incomplete data to be generated. Furthermore, the organization must divide the target population in a way that allows each $\mathrm{CHW}$ to generate the same level of income. The salaried model ensures equity between CHWs and eliminates any desire for falsification of entries but removes a level of motivation that may be important for more complex or uncomfortable data surveys.

A local pharmacy offers CHWs a monthly salary to provide directly observed therapy to its patients suffering from HIV or tuberculosis. The pharmacy wants to ensure that patients are following treatment regimens and will continue to purchase medicine from their store. During the observation, CHWs send real-time reports to the pharmacy using a messaging service like FrontLine SMS. This tool allows data to be transferred to a computer via text message in areas of limited data connectivity, providing an avenue for communication and accountability between the CHWs and the store. CHWs text their observations or questions into a central database that is monitored and responded to in real-time by the resident medical professional. This mHealth system provides community members with a direct line of communication to the pharmacy and provides the pharmacy with a method to ensure the effectiveness of its $\mathrm{CHW}$ payments. 


\section{REFERRAL BuSINESS MODEL}
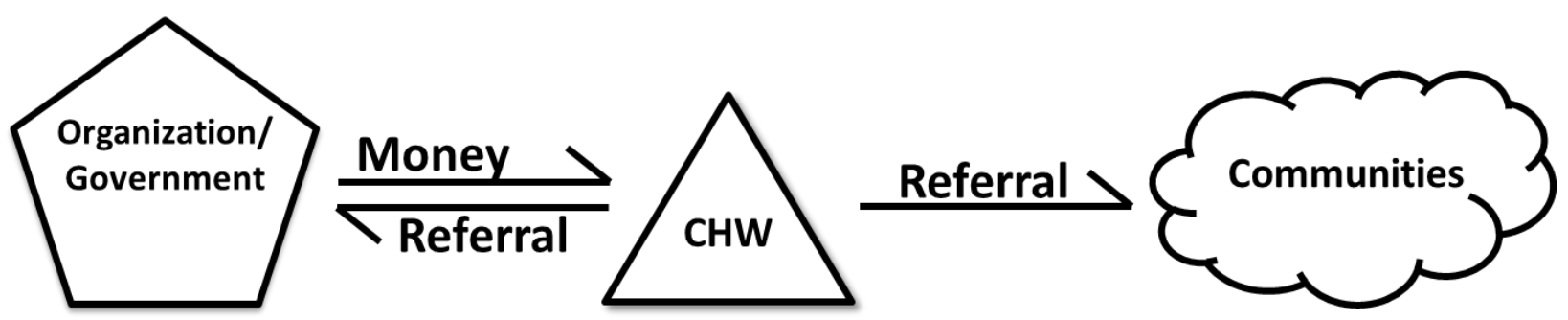

FIGURE 6

REFERRAL BUSINESS MODEL

- The CHW partners with health facility

- The CHW monitors community members in treatment programs

- The health facility pays the CHW for each successful attendance

A CHW can directly improve community health by ensuring adherence to treatments prescribed to community members. Government entities, NGOs or the facilities themselves may be willing to compensate $\mathrm{CHW}$ in return for attendance for certain treatment programs in order to minimize wasting limited resources. CHWs could be given a list of community members assigned to attend certain treatment programs in town. During house visits the CHWs would serve reminders, offer travel options, and may even agree to escort patients to the facility. The CHWs would be paid based on the attendance of those from their community.

CHWs partner with a local clinic to offer comprehensive maternal health coverage using a service such as the MOTECH mHealth program. MOTECH is a widely used open-source platform originally developed by the Grameen Foundation in Ghana that provides applications for an array of uses, ranging from patient data management to supply chain tracking. The local clinic sets up the MOTECH utility to track pregnant women's progression, coordinate CHWs for timely home visits, and offer immunization reminders. The CHWs are able to log into the MOTECH utility in order to track their patients and coordinate with other CHWs in regards to important observations about certain cases. CHWs are provided compensation for patient compliance, adherence, and attendance for checkups at the local clinic. CHWs also offer educational videos from the MOTECH utility to patients for a small fee.

\section{HoMe CaRe Business MOdeL}

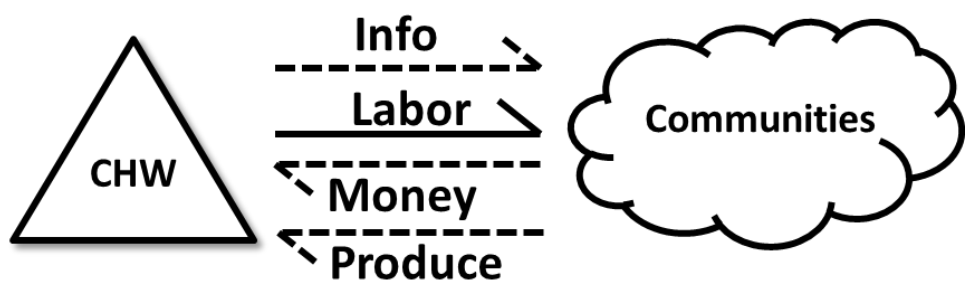

FIGURE 7

HOME CARE BUSINESS MODEL

- The CHWs help community members with home activities

- Community members pay CHWs either through money or goods

- External organizations may provide CHWs a stipend for activity completion 
CHWs develop an intimate relationship with their community members through their frequent home visits. CHWs could offer to help with home activities for a small fee. These may include cooking and cleaning for the sick or engaging in joint ventures like kitchen gardens and greenhouse farming. In return for this help, CHWs could be paid directly or offered a portion of cultivated goods. In the case of a joint farming venture, CHWs might also transport goods to the marketplace. This model is particularly relevant in regions with high incidence of HIV/AIDS as well as malnutrition. CHWs could use mHealth nutritional tracking programs to ensure that members are eating the proper foods and can tailor the kitchen gardens accordingly.

CHWs partner with an agricultural training center to learn how to effectively grow kitchen gardens, herb gardens, arrow root pits, and other locally-relevant farming endeavors. CHWs receive seeds for nutritious plants that they use to cultivate kitchen gardens for AIDS patients. While HIV patients are increasingly getting access to anti-retroviral drugs, access to nutritious food is still a major problem. With this model, patients gain access to nutritious foods and the CHW gets a few vegetables every week as payment for their help in cultivating the garden. The CHW introduces a text-based mHealth nutritional program to each patient that logs nutrition so that subsequent HIV treatment can be customized accordingly. In parallel, the training center that originally gifted the seeds for this garden uses the opportunity to conduct a longitudinal study between different seed varieties by training CHWs to use different seeds at each home. CHWs are paid a small fee by the training center at the completion of each growing cycle in return for data collected. This is a win-win situation for the CHWs, HIV patients, training center, mHealth venture and the public health authorities.

\section{Regulatory BuSINESS MODEL}

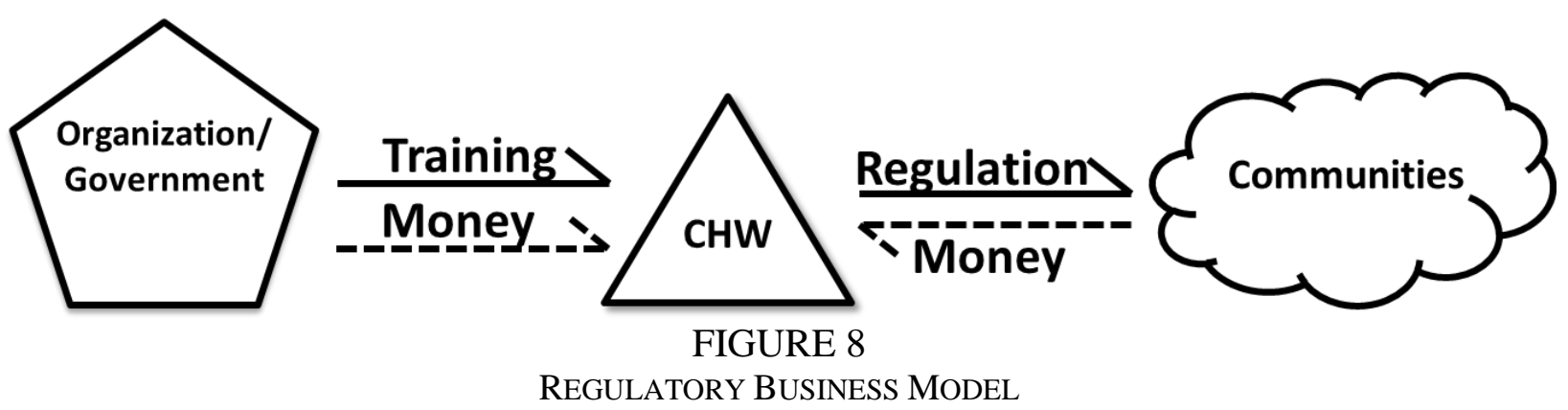

- An organization trains CHWs to inspect restaurants and other public establishments

- CHWs teach owners about proper hygiene and sanitation standards

- CHWs inspect and certify facilities

- CHWs are paid a stipend by the external entity managing the venture

CHWs are responsible for the health of their communities. Through proper compensation, CHWs could broaden their scope from house visits to also improving the cleanliness of local businesses through sanitary inspections and certifications. CHWs would be trained by an organization on hygiene, proper food preparation conditions, sanitation facilities, and related health concerns. CHWs would then pass this knowledge on to small businesses and public facilities. They would inspect and certify these businesses and give them prominently visible certificates. External nonprofit or for-profit organizations, or the small business community itself, would pay for these services. This model is extremely relevant in developing countries where public health can be 
directly correlated with the quality of sanitation facilities and small eateries. In fact, when our team launched the first telemedicine system in rural Kenya, we were asked by doctors as well as the Ministry of Health and Public Sanitation to include questions about water sources and sanitation facilities in the patient questionnaire.

The business council of a small town works with an NGO to train CHWs to survey the health conditions of various types of establishments that process or serve food. Acceptable standards are agreed upon by all members as well as other stakeholders such as public health authorities. Businesses pay a small fee to the CHWs in order to register for health evaluations. Groups of CHWs then make unannounced visits to each business and enter their observations into an online database. All of the $\mathrm{CHWs}$ present their findings to the council and provide public displays to those businesses that meet the agreed upon standards. This process improves the overall health conditions of the community while recognizing businesses that practice good hygiene and providing a means of income for CHWs. The database of food processing centers, public sanitation facilities, and small businesses can be utilized by public health authorities as well as mHealth ventures to look for common or emergent health concerns.

\section{CONCLUSION}

This article informs innovators seeking to transform volunteer-based CHW programs into effective, accountable and economically sustainable endeavors. The central thesis across this typology is that mHealth systems can be effective tools to solve healthcare problems and empower communities. The revenue models described in this article open doors for the integration of mHealth ventures that enable, complement, or augment CHWs while meeting community health needs. A related study has identified a host of common financial, technical, contextual and organizational barriers and failure modes that adversely impact the feasibility, sustainability and scalability of mHealth ventures ${ }^{14}$. An understanding of the most relevant failure modes for each of these revenue models can provide deeper insights to innovators striving

to develop their own $\mathrm{CHW}$-driven mHealth programs ${ }^{21}$. These models can be refined for specific settings and combined together to yield hybrid models with multiple stakeholders and revenue streams. Success ultimately depends on the inclusion of relevant stakeholders and development of practical technological, organizational and financial models that create win-win situations for all parties striving to tackle these complicated last mile healthcare challenges.

\section{REFERENCES}

${ }^{1}$ Daar, Abdallah S., Peter A. Singer, Deepa Leah Persad, Stig K. Pramming, David R. Matthews, Robert Beaglehole, Alan Bernstein, Leszek K. Borysiewicz, Stephen Colagiuri, Nirmal Ganguly, Roger I. Glass, Diane T. Finegood, Jeffrey Koplan, Elizabeth G. Nabel, George Sarna, Nizal Sarrafzadegan, Richard Smith, Derek Yach and John Bell. "Grand challenges in chronic non-communicable diseases." Nature 450 (November 2007): 494-496.

${ }^{2}$ Global Health Workforce Alliance. Global Experience of Community Health Workers for Delivery of Health Related Millennium Development Goals: A Systematic Review, Country Case Studies, and Recommendations for Integration into National Health Systems. World Health Organization, 2010. 
${ }^{3}$ Singh, Prabhjot and Dave A. Chokshi. "Community Health Workers - A Local Solution to a Global Problem." The New England Journal of Medicine, no. 369 (September 2013): 894-896.

${ }^{4}$ Trause, Danielle, Sarah Peterson, Nathan Doty, Alyssa Liguori, Katelyn Holmes, Linda Kanzleiter, Khanjan Mehta, "The Diverse Roles of Community Health Workers: Cues for Technology Innovations," Humanitarian Technology: Science, Systems and Global Impact Conference, Boston, May 2014

${ }^{5}$ Blaya, Joaquin A. , Hamish S.F. Fraser, and Brian Holt. "E-health technologies show promise in developing countries." Health Aff (Millwood) 29, no. 2 (February 2010): 244-251.

${ }^{6}$ Meier, Carlos A., Maria C. Fitzgerald, and Joseph M. Smith. "eHealth: Extending, Enhancing, and Evolving Health Care." Annual Review of Biomedical Engineering 15 (July 2013): 359-382.

${ }^{7}$ Gilson, Lucy, Gill Walt, Kris Heggenhougen, Lucas Owour-Omondi, Myrtle Perera, David Ross, Ligia Salazar. "National community health worker programs: how can they be strengthened?" Journal of Public Health Policy 10, no. 4 (1989): 518-532.

${ }^{8}$ Witmer, Anne, Sarena D. Seifer, Leonard Finocchio, Jodie Leslie, and Edward H. O’Neil. "Community health workers: integral members of the health care work force." American Journal of Public Health 85, no. 8 Pt 1 (1995): 1055-1058.

${ }^{9}$ Lemaire, Jeannine. "Scaling Up Mobile Health: Elements Necessary For the Successful Scale Up of mHealth in Developing Countries." Advanced Development for Africa, 2011.

${ }^{10}$ Text to Change. Pilotitis, the biggest disease in mHealth. Amsterdam, October 6, 2010.

${ }^{11}$ Chamberlain, Sarah. Pilot-itis: What's the cure? . BBC World News, June 20, 2012.

${ }^{12}$ Useem, Andrea. Mobile health initiatives look to service providers for scale. Devex Impact. Devex Impact, December 11, 2012.

${ }^{13}$ Lewis, Trevor, Christina Synowiec, Gina Lagomarsino, and Julian Schweitzer. "E-health in low- and middle-income countries: findings from the Center for Health Market Innovations." Bull World Health Organ (World Health Organization) 90, no. 5 (2012): 332-340.

${ }^{14}$ Sundin, Phillip, Jonathan Callan, Khanjan Mehta, "Why do Entrepreneurial mHealth Ventures in the Developing World Fail to Scale?” ASME Engineering for Global Development (Under Review)

${ }^{15}$ Qin, Rosie, Rachel Dzombak, Roma Amin, and Khanjan Mehta. "Reliability of a Telemedicine System Designed for Rural Kenya." Journal of Primary Care \& Community Health 4, no. 3 (2013): 177-181.

${ }^{16}$ Living Goods. Living Goods. 2013. livinggoods.org.

${ }^{17}$ Omokhodion, Folashade O. "Low back pain in a rural community in South West Nigeria." (West African Journal of Medicine) 21, no. 2 (April-June 2002): 87-90. 
${ }^{18}$ Jha, Priya, Esha Kalra, Meredith Puleio, Atanu Ghosh, Miranda Beckman, and Victoria Jennings. "CycleTel ${ }^{\mathrm{TM}}$ : Expanding Access to Family Planning through Mobile Phones." Proceedings of M4D 2012 28-29 February 2012 New Delhi, India 28, no. 29 (2012): 51.

${ }^{19}$ Praekelt Foundation. txtalert. www.praekeltfoundation.org/txtalert.html.

${ }^{20}$ Baye, Eric, Geneviève Bois, Gladys Anguezomo, and Maximilian de Courten. "SMS Diabetes in Gabon: Changing Diabetes, one SMS at a Time." Global Health: Interconnected Challenges, Integrated Solutions. Geneva: Geneva Health Forum, 2012.

${ }^{21}$ Callan, Jonathan, Phillip Sundin, Stephen Suffian, Khanjan Mehta, "Designing Sustainable Revenue Models for CHW-Centric Entrepreneurial Ventures," Global Humanitarian Technology Conference, San Jose, CA, Oct 2014 